\title{
Magnetic resonance imaging findings of patients with neck pain in Erbil City
}

\begin{tabular}{l}
\hline \multicolumn{1}{c}{ Rahmattulla MR Ubaid $^{1}$ Salwa A. Al-Najjar ${ }^{2 *}$} \\
\hline Abstract \\
Background and objective: Neck pain is one of the most common symptoms in the \\
general population; several work-related and individual factors have been verified as being \\
related to neck pain. This study aimed to determine the pathologic MRI findings of patients \\
presented with neck pain and assess its association with some probable risk factors for \\
cervical spine lesions.
\end{tabular}

Methods: This descriptive cross-sectional study involved a convenient sample of 100 patients with neck pain referred to the radiology department of Rizgary teaching hospital in Erbil for Magnetic Resonance Imaging examination of the cervical spine from June 2013 to February 2014.

Results: The age of the patients ranged from 21 to 70 years, with a mean age \pm SD of $40.19 \pm 10.44$ years. Around $42 \%$ of patients were between $30-39$ years, and $60 \%$ were females. Clinical symptoms of the patients revealed that $51.6 \%$ had radicular pain with cervical MR images abnormalities in $59 \%$ of the patients. The most common degenerative abnormality on MRI was disc bugle, which accounted for $37.3 \%$ of total degenerative changes. MRI findings were most common at the C5/C6 level. A significant association was found between the cervical MRI abnormalities and the occupation and practicing neck $(P=0.03$ and 0.001 , respectively). However, no association was found with age, gender, $\mathrm{BMI}$, and smoking habits of the patients. Also, there was a highly significant $(P=0.001)$ association between radicular pain, with disc bulge and disc protrusion.

Conclusion: MRI is a useful investigation tool for diagnosing different clinical conditions among patients with cervical pain. Considering the diagnostic accuracy and costeffectiveness, it is the key diagnostic tool for early detection of the degenerative changes and initiating appropriate treatment.

Keywords: Cervical Spine; Cervical degeneration; Spondylosis; MRI.

\section{Introduction}

Neck pain is a commonly encountered complaint in medical practice. In population studies, $20-65 \%$ of women and $15-40 \%$ of men have experienced neck and shoulder symptoms during their lives, and the prevalence increases with age. ${ }^{1,2}$ Neck and shoulder pain are multi-etiological, and discogenic pain is thought to originate from annular tears or disc degeneration. ${ }^{3-6}$ Neck pain is second only to low back pain as the most common musculoskeletal disorder in population surveys and primary care, and, like low back pain, it poses significant health and economic burden, being a frequent source of disability. ${ }^{7}$ There are seven cervical vertebrae and eight cervical nerves and intervertebral discs are located between the vertebral bodies of $\mathrm{C} 2-\mathrm{C} 7$, serve as force dissipaters, transmitting compressive loads throughout a range of motion. $^{8-10}$ Initial changes in the disc include loss of the water content and changes in the relationship of the glucose aminoglycans and other polymers within the disc, leads to disc degeneration. ${ }^{13,14}$

${ }^{1}$ Ministry of Health, Erbil, I raq.

${ }^{2}$ Department of Surgery, College of Medicine, Hawler Medical University, Erbil, I raq

* Correspondence: drsalwarad25@yahoo.com 
The cervical spine is a common site for degenerative changes often caused by the aging process as the greatest spinal mobility happens in the neck. ${ }^{15-19}$ The degenerative alterations of the cervical spine are usually referred to as cervical spondylosis. ${ }^{20}$ Studies have shown that the biomechanics of this region is a function of many genetic and developmental influential factors such as age, sex, occupation, and weight and have an influence on the vulnerability of the cervical spine to degenerative change. Even some harmless daily activities such as standing, walking, and lying down can trigger spine problems. $^{21}$ There is evidence to show that various work-related factors, such as repetitive tasks and working with the arms raised or the neck bent forward, are related to neck and shoulder pain. ${ }^{22}$ Symptoms caused by cervical spondylosis can be categorized broadly into the three clinical syndromes of axial neck pain, cervical radiculopathy, and cervical myelopathy. Patients can have a combination of these syndromes. ${ }^{21,22}$ Magnetic resonance imaging (MRI) is often used for patients with cervical spine disorders, and it has a high sensitivity for detecting early disc diseases. ${ }^{22-24}$ On MRI, the normal adult disc presents an intermediate to low signal intensity on T1-weighted images (T1WI), when compared to the bone marrow in the adjacent vertebral bodies. T1 weighted scans are used to visualize structural abnormalities, marrow infiltration, and contrast enhancement (using Gadolinium chelate). On T2-weighted images (T2WI), the normal discs have high signal, and the bright nucleus pulposus and the inner annulus are indistinguishable. ${ }^{13}$ T2 weighted scans are used to detect spinal cord abnormalities, including degenerative disease, edema, gliosis, demyelination, and neoplasia, and to evaluate the thecal sac dimensions. ${ }^{8}$ There are few studies in our region on the association between the influential factors and the radiological findings in cervical disc degenerative diseases, as compared to the ample research on the lumbar discs diseases due to the higher incidence of the latter. Accordingly, this study aimed to determine the pathologic MRI findings of patients presented with neck pain and assess its association with some probable risk factors for cervical spine lesions among patients referred to the cervical MRI unit in Erbil City.

\section{Methods}

This descriptive cross-sectional study included 100 patients with a history of neck pain and/or radicular pain in the upper limbs who referred for cervical MRI to the Radiology department of Rizgary teaching hospital in Erbil city, Kurdistan region of Iraq during June 2013 to February 2014. Exclusion criteria were those patients under ten years of age and those with a history of trauma to the cervical spine or surgery of the cervical spine. For data collection, a special questionnaire was designed to collect data on sociodemographic characteristics of the enrolled patients, including age, gender, occupation, weight, height, exercise, and smoking. The second part of the questionnaire included signs and symptoms of the neck complaint, in addition to MRI findings. Initially, all the cases were interviewed and a questionnaire filled in. Then the MR images were taken by MAGNETOM Avanto 1.5 Tesla -SIEMENS /Germany. Altogether 500 cervical discs of 100 patients with at least a chief complaint of neck pain were assessed, and no MRI was excluded due to inadequate visibility or artifacts. The patients lay supine with the neck extended. The surface coil of the neck was placed. Scout views in the sagittal direction were obtained with a fast spin-echo (FSE) sequence. Standard MRI images obtained were T1-weighted sagittal images (T1WSI), T2-weighted sagittal images (T2WSI), and T2-weighted axial images (T2WAI). Magnetic resonance myelography using FSE sequences (T1Wl: time of repetition/time of echo 
(TR/TE) 450-550/9.7-39 millisecond; T2WI: 3000-4000/12-127 millisecond; slice thickness $4 \mathrm{~mm}$, slice gap of $0.6 \mathrm{~mm}$, field of view (FOV) $28 \mathrm{~cm}$ was used for sagittal images and $18 \mathrm{~cm}$ for axial images, matrix $320 * 70$ were used for $\mathrm{T} 1 \mathrm{WI}$ and $320 * 100$ for T2WI for sagittal images, matrix $256^{*} 100$ for $\mathrm{T} 1 \mathrm{WI}$ and $256^{*} 85$ for T2WI for axial images. Sagittal and axial images were obtained, including the atlanto occipital joints through at least the $\mathrm{C} 7$ to $\mathrm{T} 1$ intervertebral disc. All the images were reported by specialist radiologists. Standard terms were used to classify disc based on a two-dimensional assessment of the disc contour in the transverse plane. A normal disc was considered when there is no disc extension beyond the confines of the vertebral body. Disc bulging was considered to be present when disc material bulged beyond the confines of the vertebral body (involving $50 \%$ to $100 \%$ of the disc circumference) and is not considered a form of herniation. The disc was considered protruded when a focal mass with high signal intensity on T2 extended beyond the margins of the adjacent vertebral bodies and the base of the herniated disc material is broader than the apex and considered extruded when a focal mass with high signal intensity on T2 extended beyond the margins of the adjacent vertebral bodies and the base of the herniation is narrower than the apex. If the displaced disc material has no connection with the parent disc, it is called a "sequestrated fragment." Disc narrowing was considered to be present when the disc space was less than the adjacent vertebral bodies' disc spaces. Dorsal osteophytes or spurs was considered to present if there was a sharp low signal edge to the body of the vertebra. ${ }^{13,19}$ The statistical package for the social sciences (version 16) was used for data entry and analysis. Chi-square was used to compare the categorical variables. A $P$ value of $\leq 0.05$ was considered as statistically significant. The study protocol was approved by the research ethics committee of the College of MedicineHawler Medical University. Also, verbal approval was guaranteed from the administration of Rizgary Teaching Hospital, and the verbal consent was taken from all the enrolled patients. All the patients were informed about the purpose of the study and were assured of the confidentiality of the obtained information.

\section{Results}

\section{Socio-demographic characteristics of} the patients

A total of 100 patients with neck pain were enrolled in the current study; their age ranged from 21 to 70 years, with a mean age \pm SD of $40.19 \pm 10.44$ years, and $42 \%$ of them were between $30-39$ years, followed by $25 \%$ of those aged $40-49$ years. Among the patients, $60.0 \%$ were females with a male to female ratio of 0.66:1. Other socio-demographic characteristics of the patients are found in Table1.

\section{Clinical symptoms of the patients}

Clinical symptoms of the patients revealed that $51.6 \%$ had radicular pain, mostly $(47.6 \%)$ in both upper limbs (Table 2 ). 
Table 1: Socio-demographic characteristics of the patients.

\begin{tabular}{lcc}
\hline Variables & No. & (\%) \\
\hline Age groups & 12 & $(12.0)$ \\
$20-29$ & 42 & $(42.0)$ \\
$30-39$ & 25 & $(25.0)$ \\
$40-49$ & 15 & $(15.0)$ \\
$50-59$ & 6 & $(6.0)$ \\
$\geq 60$ & & \\
Gender & 40 & $(40.0)$ \\
Male & 60 & $(60.0)$ \\
Female & & \\
Occupation & 31 & $(31.0)$ \\
Office workers & 29 & $(29.0)$ \\
Manual workers (construction, Farming, and etc) & 40 & $(40.0)$ \\
Others (housewives, retired, and etc) & & \\
Body Mass Index (BMI) & 30 & $(30.0)$ \\
Normal & 30 & $(40.0)$ \\
Overweight & 30 & $(30.0)$ \\
Obese & & \\
Neck exercise & & $(73.0)$ \\
No & 73 & $(27.0)$ \\
Yes & 27 & $(66.0)$ \\
Smoking & & $(34.0)$ \\
No & 66 & \\
Yes & 34 & \\
\hline
\end{tabular}

Table 2: Clinical symptoms of the patients.

\begin{tabular}{lcccccccc}
\hline Symptoms & \multicolumn{2}{c}{ Right upper limb } & \multicolumn{2}{c}{ Left upper limb } & \multicolumn{2}{c}{ Both limbs } & \multicolumn{2}{c}{ Total } \\
& No & $(\%)$ & No & $(\%)$ & No & $(\%)$ & No & $(\%)$ \\
\hline Radicular pain & 20 & $(31.7)$ & 13 & $(20.6)$ & 30 & $(47.6)$ & 63 & $(51.6)$ \\
Paresthesia & 6 & $(23.0)$ & 10 & $(38.5)$ & 10 & $(38.5)$ & 26 & $(21.3)$ \\
Numbness & 5 & $(27.7)$ & 4 & $(22.2)$ & 9 & $(50.0)$ & 18 & $(14.8)$ \\
Weakness & 6 & $(40.0)$ & 2 & $(13.3)$ & 7 & $(46.6)$ & 15 & $(12.3)$ \\
& & & & & & & & \\
*Total & 37 & $(30.3)$ & 29 & $(23.8)$ & 56 & $(45.9)$ & 122 & $(100.0)$ \\
\hline * Some patients had more than one symptom & & & & & \\
\hline
\end{tabular}




\section{MRI findings among the patients}

Cervical MR images were normal in $41 \%$ of the patients. It also showed signs of degenerative diseases, including disc bulging, dehydration, herniation, spinal canal stenosis, disc space narrowing, osteophytosis, posterior longitudinal ligament thickening, and facet joint arthrosis in $59 \%$ of the patients (Figure 1 ).
T2WSI and T2WAl showed straightening of the cervical spine, disc dehydration at $\mathrm{C} 4 / \mathrm{C} 5$ and $\mathrm{C} 5 / \mathrm{C} 6$ levels with a disc bulge at C5/C6 level. All patients with degenerative and non-degenerative findings had straitening of the cervical spine, no extrusion or sequestration was found among the patients (Figure 2).



Figure 1: Distribution of normal and abnormal MRI findings among the patients.

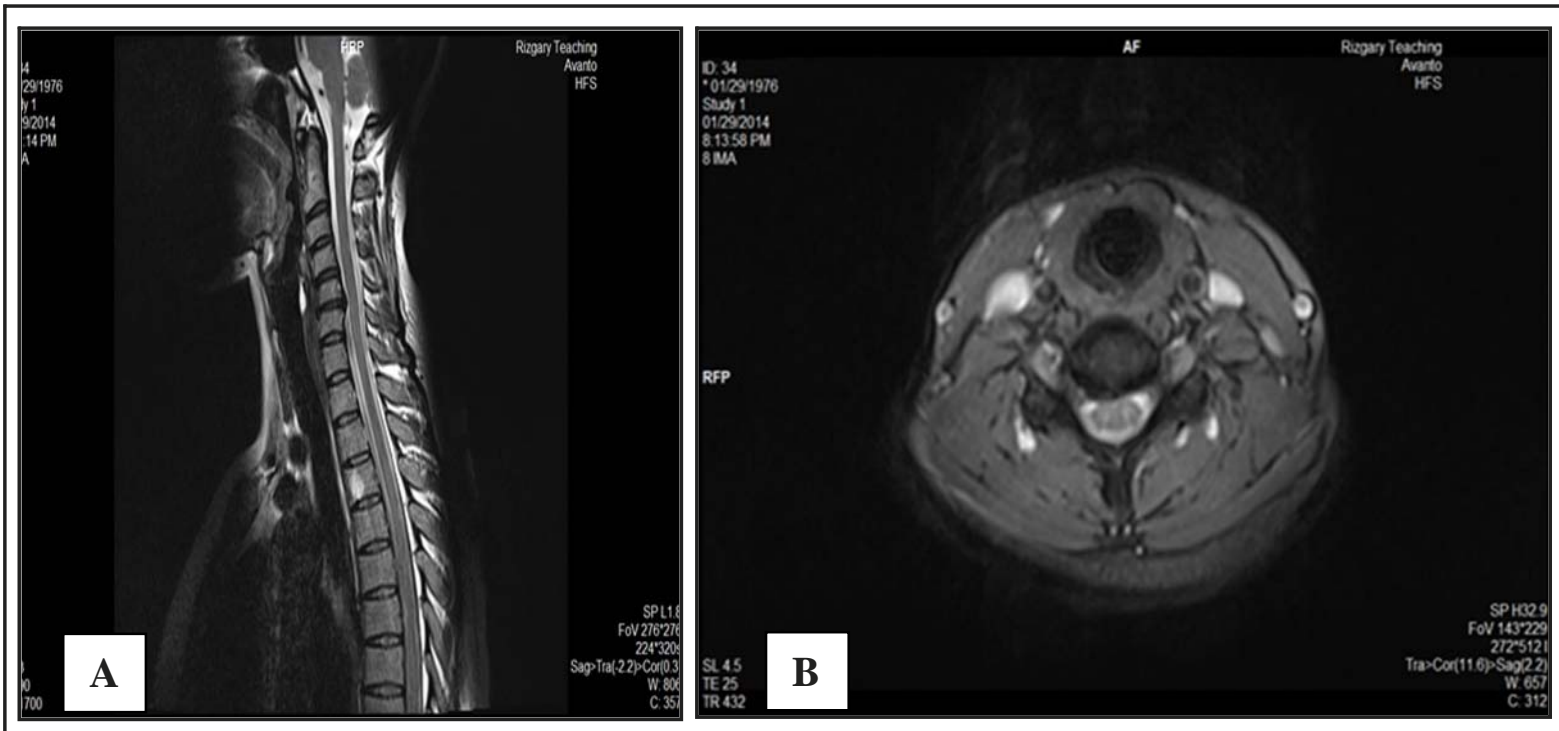

Figure $2(A, B):$ T2 sagittal and axil view of cervical spine, showing degenerative changes at level of C5-C6 with right side nerve compression. 
The most common degenerative abnormality on MRI was disc bulge, which constituted $74.5 \%$ of total patients with abnormal MRI and accounted for $37.3 \%$ of total degenerative changes. However, those with disc dehydration and disc protrusion constituted $57.6 \%$ and $22.0 \%$ of total patients with abnormal MRI findings and accounted for $28.8 \%$ and $11.0 \%$, of total degenerative changes. Other details of MRI degenerative changes are shown in Table 3. Regarding the most common levels for the three frequent degenerative lesions in the cervical spines, 59.3\% occurred at the level of C5- $\mathrm{C} 6$, where disc bulge constituted $48.1 \%$ of the degenerative changes, followed by disc dehydration and disc protrusion $(37.0 \%$ and $14.8 \%$, respectively) as shown in Table 4.

Table 3: Types and distribution of different pathological degenerative changes among the patients.

\section{MRI findings}

\begin{tabular}{lccc} 
Degenerative MRI findings & Frequency & $\begin{array}{c}\text { \% of patients with } \\
\text { abnormal MRI }\end{array}$ & $\begin{array}{c}\text { \% of total degenerative } \\
\text { findings }\end{array}$ \\
\hline Disc bulge & 44 & $(74.5)$ & $(37.3)$ \\
Disc dehydration & 34 & $(57.6)$ & $(28.8)$ \\
Disc protrusion & 13 & $(22.0)$ & $(11.0)$ \\
Disc space narrowing & 8 & $(13.5)$ & $(6.8)$ \\
Osteophytosis & 6 & $(10.2)$ & $(5.1)$ \\
PLL hypertrophy & 5 & $(8.4)$ & $(4.2)$ \\
Facet joint arthrosis & 4 & $(6.7)$ & $(3.4)$ \\
Spinal canal stenosis & 2 & $(3.4)$ & $(1.7)$ \\
Cord compression & 2 & $(3.4)$ & $(1.7)$ \\
*Total & $\mathbf{1 1 8}$ & $\mathbf{( 5 0 . 0 )}$ & $\mathbf{( 1 0 0 . 0 )}$ \\
\hline
\end{tabular}

* Some patients had more than one degenerative change.

Table 4: Most common levels for the three frequent degenerative findings among the patients.

\begin{tabular}{lcc}
\hline Type of pathology & $\begin{array}{c}\text { Most common level } \\
\text { C5- C6 }\end{array}$ & $\begin{array}{c}\text { Second most common level } \\
\text { C6- C7 }\end{array}$ \\
\hline Disc Bulge & $26(48.1)$ & $18(41.0)$ \\
Disc Dehydration & $20(37.0)$ & $14(41.7)$ \\
Disc protrusion & $8(14.8)$ & $5(38.5)$ \\
Total & $54(59.3)$ & $37(40.7)$ \\
\hline
\end{tabular}


Association between MRI findings and certain socio-demographic characteristics of the patients:

The majority of the patients with abnormal MRI finding were in the third and fourth decade of life $(40.7 \%$ of those aged $30-39$ years and $23.7 \%$ of those aged $40-49$ years, respectively), with no statistically significant association between MRI findings and age groups of the patients, $(P=0.35)$. The mean age \pm SD of patients with degenerative and those with no degenerative changes were $42.07 \pm 11.11$, and $37.49 \pm 8.84$ years, respectively. There was no significant statistical difference between the gender and the BMI of the patients in relation to the MRI findings ( $P=0.86$ and 0.212 , respectively). Manual workers had significantly $(P=0.03)$ more abnormal findings $(39.0 \%)$ compared to the other occupations. However, those who had not practiced neck exercise significantly $(P=0.001)$ had higher abnormal MRI findings, MRI abnormalities were reported among $94.9 \%$ of patients who did not practice exercise of the neck versus only $5.1 \%$ of those performed exercise of the neck. MRI findings were not significantly $(P=0.37)$ associated with smoking among the patients (Table 5).

Table 5: Association between MRI findings and certain socio-demographic characteristics of the patients.

\begin{tabular}{|c|c|c|c|}
\hline \multirow[b]{2}{*}{ Variables } & \multicolumn{2}{|c|}{ MRI findings } & \multirow[b]{2}{*}{$P$ value } \\
\hline & $\begin{array}{l}\text { Normal } \\
\text { No. (\%) }\end{array}$ & $\begin{array}{l}\text { Abnormal } \\
\text { No. (\%) }\end{array}$ & \\
\hline \multicolumn{4}{|l|}{ Age groups } \\
\hline 20- 29 & $7(17.0)$ & $5(8.5)$ & \multirow{5}{*}{0.35} \\
\hline 30- 39 & $18(43.9)$ & $24(40.7)$ & \\
\hline 40- 49 & $11(26.8)$ & $14(23.7)$ & \\
\hline 50- 59 & $4(9.8)$ & 11(18.6) & \\
\hline$\geq 60$ & $1(2.4)$ & $5(8.5)$ & \\
\hline \multicolumn{4}{|l|}{ Gender } \\
\hline Male & $16(39.0)$ & $24(40.7)$ & \multirow[t]{2}{*}{0.86} \\
\hline Female & $25(61.0)$ & $35(59.3)$ & \\
\hline \multicolumn{4}{|l|}{ Occupation } \\
\hline Office workers & $15(36.6)$ & $16(27.1)$ & \multirow{3}{*}{0.03} \\
\hline $\begin{array}{l}\text { Manual workers (construction, } \\
\text { farming, and ...etc) }\end{array}$ & $6(14.6)$ & $23(39.0)$ & \\
\hline Others (housewives, retired,etc.) & $20(48.8)$ & $20(33.9)$ & \\
\hline \multicolumn{4}{|l|}{ Body Mass Index } \\
\hline Normal & $16(39.0)$ & $14(23.7)$ & \multirow{3}{*}{0.212} \\
\hline Overweight & $13(31.7)$ & $27(45.8)$ & \\
\hline Obese & $12(29.3)$ & $18(30.5)$ & \\
\hline \multicolumn{4}{|l|}{ Neck exercise } \\
\hline No & $17(41.5)$ & $56(94.9)$ & \multirow[t]{2}{*}{0.001} \\
\hline Yes & $24(58.5)$ & $3(5.1 \%)$ & \\
\hline \multicolumn{4}{|l|}{ Smoking } \\
\hline No & $25(61.0)$ & 41(69.5) & \multirow[t]{2}{*}{0.37} \\
\hline Yes & $16(39.0)$ & $18(30.5)$ & \\
\hline
\end{tabular}


Association between radicular pain, with disc bulge and disc protrusion

There was a highly significant $(P=0.001)$ statistical association between radicular pain and disk bulge, where $47.7 \%$ of the patients had symmetrical disc bulge, compared to those had the asymmetrical right or let disc bulge $(25.0 \%$ and $27.3 \%$, respectively). However, there was a highly significant $(P=0.001)$ statistical association between radicular pain and disc protrusion too, where $38.5 \%$ of the patients had central disc protrusion, compared to those had right or left paracentral disc protrusion $(23.0 \%$ and $38.5 \%$, respectively) as shown in Table 6.

\section{Discussion}

The cervical degenerative disease frequently occurs, and it is often difficult to differentiate pathological changes from the normal aging process. Within the first two decades of life little degenerative changes occur in the spine, it would be more apparent within the third decade and onwards, and start at the level of cervical discs and is most frequent at C5/C6 and $\mathrm{C} 6 / \mathrm{C} 7 .{ }^{25}$ In this study, the clinical symptoms of the patients were radicular pain, paraesthesia, numbness, and weakness, while a study in North Nigeria showed that the patients' symptoms included neck pain, radicular pain (involving arm, shoulder, and hand), gait abnormalities, motor dysfunction (paralysis, paresis), and sensory abnormalities (paresthesia, tingling sensation). ${ }^{26}$ Another study in China revealed that $22.5 \%$ of the patients were referred with radiculopathy. ${ }^{27}$ In this study, cervical MR images showed signs of degenerative diseases in $59 \%$ of the patients. Almost similar results were reported in a study in Australia and Nigeria, which revealed that more than $70 \%$ of the patients reported intervertebral disc degeneration on MRI finding. ${ }^{28,29}$ In our study, the most common degenerative abnormality on MRI was disc bugle, which constituted $74.5 \%$ of total patients with abnormal MRI and accounted for $37.29 \%$ of total degenerative changes. However, those with disc dehydration and disc protrusion constituted $57.6 \%$ and $22.0 \%$ of total patients with abnormal MRI findings and accounted for $28.8 \%$ and $11.0 \%$, of total degenerative changes. Almost similar results were reported in a Nigerian study. ${ }^{29}$ Another study in Northern Nigeria revealed that osteophytes and disc dehydration were the most common findings among patients with cervical degeneration. ${ }^{26}$

Table 6: Association between radicular pain, with disc bulge and disc protrusion.

\begin{tabular}{lccccc}
\hline \multirow{2}{*}{ Variables } & \multicolumn{5}{c}{ Radicular pain } \\
& Right side & Left side & Central & Total & P value \\
\hline Disc bulge & & & & & \\
Asymmetrical (Right) & $9(18.8)$ & $1(8.3)$ & $1(4.8)$ & $11(25.0)$ & \\
Asymmetrical (Left) & $1(9.0)$ & $10(83.3)$ & $1(4.8)$ & $12(27.3)$ & 0.001 \\
Symmetrical & $1(9.0)$ & $1(8.3)$ & $19(90.4)$ & $21(47.7)$ & \\
Total & $\mathbf{1 1 ( 2 5 . 0 )}$ & $\mathbf{1 2 ( 2 7 . 3 )}$ & $\mathbf{2 1 ( 4 7 . 7 )}$ & $\mathbf{4 4 ( 1 0 0 . 0 )}$ & \\
Disc protrusion & & & & & \\
Right paracentral & $3(100.0)$ & $0(0.0)$ & $0(0.0)$ & $3(23.0)$ & \\
Central & $0(0.0)$ & $0(0.0)$ & $5(100.0)$ & $5(38.5)$ & 0.001 \\
Left paracentral & $0(0.0)$ & $5(100.0)$ & $0(0.0)$ & $5(38.5)$ & \\
Total & $\mathbf{3 ( 2 3 . 0 )}$ & $\mathbf{5 ( 3 8 . 5 )}$ & $\mathbf{5 ( 3 8 . 5 )}$ & $\mathbf{1 3 ( 1 0 0 . 0 )}$ & \\
\hline
\end{tabular}


In this study, the most common levels of the degenerative lesions in the cervical spines were at the level of C5- C6, followed by $\mathrm{C} 6-\mathrm{C} 7$ level. Almost similar results were reported in a study done in Saudi Arabia and Switzerland. ${ }^{25,30}$ While a study in China revealed that it was most common in $\mathrm{C} 3 / 4$ and $\mathrm{C} 4 / 5{ }^{27}$ In the present study, the majority of the patients with abnormal MRI findings were in the third and fourth decade of life $(P=0.35)$. The result is inconsistent with studies in Saudi Arabia and Japan, where degenerative changes tend to be more severe with advanced age. The difference could due to the small sample size and the majority of the patients included in the study were from the third and fourth decade of life. ${ }^{25,31}$ There was no significant statistical difference $(P=0.86)$ between the sex of the patients in relation to the MRI findings, where females had more cervical degenerative changes compared to males. This was in contrast to the results of a study in Nigeria. ${ }^{29}$ Another study in Japan revealed no significant gender-related differences among patients who underwent cervical MRI. ${ }^{32}$ These differences could be attributed to genetic factors in addition to a dominant number of females in the study sample. In this study, manual workers had significantly $(P=0.03)$ more abnormal findings compared to the other occupations. Similar results were reported in a study conducted in southwest Nigeria and Congo. ${ }^{33,34}$ Carrying loads on the head imposes a considerable amount of strain on the axial skeleton, in addition to heavy works, and heavy load carriers are more pre-disposed to developing severe cervical spondylosis. In this study, there was no significant association between BMI and smoking in relation to cervical degenerative changes, while it was significantly associated with neck exercise. Almost similar results were found in a Japanese study, which revealed that cervical degeneration was not associated with the gender, smoking habit, sports activities and BMI of the patients. ${ }^{32}$ The study had shown a highly significant
$(P=0.001)$ statistical association between radicular pain in relation to both disk bulge and disk protrusion. In contrast to results of a study conducted in Australia, which revealed that symptomatology was not correlated with the presence of cervical degenerative joint disease, clinical symptoms such as pain level, headaches, shoulder referral, and hand radiculopathy or numbness are not reliably correlated with radiographic findings of cervical degenerative. ${ }^{35}$ There are multiple limitations to this study and possible biases. With regard to the patient population (mean 40 years), the inclusion of more patients between 50 and 70 years would be desirable because, in this age group, the degenerative processes gain momentum. However, the study groups should be more carefully selected based on neck pain history. Although we were able to present a risk evaluation for the investigated parameters such as age, spine level, disc compartment, occupation, exercise, smoking, and $\mathrm{BMI}$, we were not able to calculate the absolute power of these factors because they are interconnected. The sample size of the present study did not allow subgroup analysis of the effects of the neck exercise on patients of different genders and of different age groups. Finally, because of the small study sample, the findings have to be considered preliminary and need to be verified in a larger population.

\section{Conclusion}

This study concludes that a considerable number of patients with neck pain had cervical degeneration, mostly in the third and fourth decade of their life. The radicular pain was the main symptom, with disc bulge; disc dehydration and disc protrusion were the main degenerative findings, mainly at the level of C5-C6 and C6-C7. The degenerative changes were significantly associated with occupation and neck exercise, while it was not associated with age, gender, smoking habit, and BMI of the patients. Accordingly, 
MRI is a useful investigation tool for diagnosing different clinical conditions among patients with cervical pain. Considering the diagnostic accuracy and cost-effectiveness, it is the key diagnostic tool for initiating early and appropriate treatment. Further prevalence studies on degenerative changes should be conducted with more samples from clinical, occupational, and general populations, including more patients above the age of 50 .

\section{Competing interests}

The authors declare no competing interests.

\section{References}

1. Guzman J, Hurwitz EL, Carroll LJ, Haldeman S, Côté P, Carragee EJ, et al. A new conceptual model of neck pain: linking onset, course, and care: the bone and joint decade 2000-2010 task force on neck pain and its associated disorders. Spine 2008; 15:14-23.

2. Bovim G, Schrader H. Neck pain in the population. Spine 1994; 19(12):1307-9.

3. Rimpelä M, Rimpelä A, Vikat A, Hermansson E, Kaltiala Heino R, Kosunen E. How has adolescents' health changed over 20 years? Suomen Lääkärilehti 1997; 52:2705-12.

4. Moneta GB, Videman T, Kaivanto K, Aprill C, Spivey $M$, Vanharanta $H$, et al.Reported pain during lumbar discography as a function of annular tears and disc degeneration. Spine 1994; 19:1968-74.

5. Marchiori DM, Henderson CN. A crosssectional study correlating cervical radiographic degenerative findings to pain and disability. Spine 1996; 21(23):2747-51.

6. Salminen JJ, Erkintalo MO. Recurrent low back pain and early disc degeneration in the young. Spine 1999; 24(13):1316-21.

7. Siivola SM, Levoska S, Tervonen O, Ilkko E, Vanharanta He, Keinanen-Kiukaann S, et al. MRI changes of the cervical spine in asymptomatic and symptomatic young adults. Eur Spine J 2002; 11:358-63.

8. Runge VM. Clinical MRI. $1^{\text {st }}$ ed. USA:W.B. Saunders; 2002. P. 117.

9. Johnson R. Anatomy of the cervical spine and its related structures. In: Torg JS, ed. Athletic injuries to the head, neck, and face. $2^{\text {nd }}$ ed. St Louis, Mo: Mosby-Year Book; 1991. P. 371-83.

10. Windsor RE. Cervical spine anatomy. Medscape. 2017. (Accessed Jan 4, 2019, at https://emedicine.medscape.com/article/1948797overview).
11. Drake RL, Vogl AW. Gray's Atlas of anatomy for the students. Philadelphia: Churchill Livingstone; 2007.

12. Bogduk N, Windsor $M$. The innervation of the cervical intervertebral discs. Spine 1988; 13:28.

13. Van Goethem JW, Hauwe L, Spinal imaging; diagnostic imaging of the spine and spinal cord. Berlin: Springer-Verlag Berlin Heidelberg; 2007.

14, Marcotte PJ, Burnett MG. Degenerative disease of the cervical spine. In: Moore AJ, Newell DW. (Eds.): Neurosurgery. Principles and Practice. Berlin: Springer-Verlag Berlin Heidelberg; 2005. P. 533-3.

15. Clarck CR. Degenerative conditions of the cervical spine: differential diagnosis and non-operative management. In: Frymoyer JW. The Adult Spine, principles and practice. $2^{\text {nd }}$ ed. Philadelphia: Lippincott Raven; 1997. P.1323-48.

16. Shedid S, Benzel EC. Cervical spondylosis anatomy: pathophysiology and biomechanics. Neurosurgery 2007; 60:7-13.

17. Weinstein PR, Ehni G. Lumbar spondylosis: Diagnosis, management, and surgical treatment. Chicago, USA: Year Gook Medical Publishers; 1997. P. 3.

18. Benzel EC. Biomechanics of spine stabilization. USA: Rolling Meadows; 2001.

19. Boden SD, Mc Cowin PR. Abnormal magnetic-resonance scans of the cervical spine in asymptomatic subjects. J Bone Joint Surg Am 1990; 72:1178-84.

20. Brower RS. Cervical disc disease. In: Herkowitz HN, Garfin SR. The Spine. $4^{\text {th }}$ ed. Philadelphia: WB Saunders; 1999. P. 455-92.

21. Gunning JL, Callaghan JP. Spinal posture and prior loading history modulate compressive strength and type of failure in the spine: a biomechanical study using a porcine cervical spine model. Clin Biomech 2001; 16 (6):471-80.

22. Kaiser JA, Holland BA. Imaging of the cervical spine. Spine 1998; 23:2701-12.

23. Tertti $M$, Paajanen $H$. Disc degeneration in magnetic resonance imaging: a comparative biochemical, histologic, and radiologic study in cadaver spines. Spine 1991; 16:629-34.

24. Larsson EM, Holtas S. Comparison of myelography, CT myelography and magnetic resonance imaging in cervical spondylosis and disc herniation: pre- and postoperative findings. Acta Radiol 1989; 30:23-39.

25. Ali AH, Siddiqui MA, Bedewi MA, Serhan OO. Evaluation of age-related changes in the cervical spine in Saudi Arabian adult population: Using CT Scan images. Forensic Med Anat Res 2014; 2:28-36

26. Olarinoye-Akorede SA, Ibinaiye PO, Akano A, Hamidu AU, Kajogbola GA. Magnetic Resonance Imaging findings in cervical spondylosis and cervical spondylotic myelopathy in Zaria, Northern Nigeria. Sub-Saharan Afr J Med 2015; 2:74-8. 
27. Jiang SD, Jiang LS, Dai LY. Degenerative cervical spondylolisthesis: a systematic review. Int Orthop 2011; 35(6):869-75.

28. Sambrook PN, Mac Gregor AJ, Spector TD. Genetic influences on cervical and lumbar disc degeneration: A magnetic resonance imaging study in twins. Arthritis Rheum 1999; 42:366-72.

29. Mustapha Z, Okedayo M, Ibrahim K, Abba Ali A Ahmadu MS, Abubakar A, et al. Cervical spine MRI findings in patients presenting with neck pain and radiculopathy. Int Res J Basic Clin Stud 2014; 2(2):20-6.

30. Mann E, Peterson CK, Hodler J. Degenerative marrow (Modic) changes in cervical spine MRI scans: prevalence, inter- and intra-examiner reliability and link to disc herniation. Spine 2011; 36(14):1081-85.

31. Matsumoto $M$, Okada E, Toyama $Y$, Fujiwara $H$, Momoshima S, Takahata T. Tandem age-related lumbar and cervical inter vertebral disc changes in asymptomatic subjects. Eur Spine J 2013; 22:708-13.

32. Okada E, Matsumoto $M$, Fujiwara $H$, Toyama $Y$. Disc degeneration of cervical spine on MRI in patients with lumbar disc herniation: a comparison study with asymptomatic volunteers. Eur Spine J 2011; 20(4):585-91.

33. Oguntona SA. Cervical spondylosis in South West Nigerian farmers and female traders. Ann Afr Med 2014; 13:61-4.

34. Echarri JJ, Forriol F. Influence of the type of load on the cervical spine: a study on Congolese bearers. Spine J 2005; 5(3):291-6.

35. Rudy IS, Poulos A, Owen L, Batters A, Kieliszek $\mathrm{K}$, WilloxJ, et al. The correlation of radiographic findings and patient symptomatology in cervical degenerative joint disease: a cross-sectional study. Chiropr Man Therap 2015; 23:9. 